\title{
PENDIDIKAN MULTIKULTURAL DARI PERSPEKTIF H.M. RASJIDI
}

\author{
Daru Nur Dianna \\ Universitas Muhammadiyah Surakarta \\ Jl. A. Yani, Mendungan, Pabelan, Kec. Kartasura, Kabupaten Sukoharjo, Jawa Tengah \\ 57162 \\ E-Mail: daru.nurdianna@gmail.com
}

\begin{abstract}
This paper aims to study the concept of religious thought and tolerance according to Prof. H.M. Rasjidi which will be a fundamental discussion in the concept of multicultural education. The methodology in this research is a literature study of books by Prof. H.M. Rasjidi who has a discussion about the concepts of religion and tolerance. The primary source book in this study is «Empat Kuliah Agama Islam» and «Koreksi Terhadap Dr. Harun Nasution dalam Islam Ditinjau dari Berbagai Aspeknya». Prof. H.M. Rasjidi, provides clear boundaries in the theological aspects of how Muslims have the concept of being able to live with followers of other religions. Muslims can live well together in social and economic aspects, but not in blending religion or equating all religions. According to him, religious pluralism in multiculturalism concept in the sense of equating to all of religion is something that needs to be avoided.
\end{abstract}

Keywords: H.M. Rasjidi's Thoughts, Multicultural Education, Islamic Education

\begin{abstract}
Abstrak: Paper ini memiliki tujuan untuk mengkaji pemikiran konsep Agama dan toleransi menurut Prof. H.M. Rasjidi yang akan merupakan pembahasan asasi dalam pendidikan multikultural. Metodologi dalam penelitian ini adalah studi pustaka dari buku-buku karya Prof. H.M. Rasjidi yang memiliki pembahasan mengenai konsep agama dan toleransi. Buku sumber primer dalam penelitian ini adalah buku "Empat Kuliah Agama Islam"; dan "Koreksi Terhadap Dr. Harun Nasution dalam Islam Ditinjau dari Berbagai Aspeknya". Prof. H.M. Rasjidi, memberikan batas-batasan yang jelas dalam aspek teologis bagaimana umat Islam bisa hidup bersama penganut agama lain. Umat Islam dapat hidup besama dengan baik dalam aspek sosial dan ekonomi, namun tidak dalam pencapuradukan Agama atau menyamakan semua agama. Menurutnya, pluralisme agama pada konsep multikulturalisme yang dalam artian menyamakan adalah hal yang perlu dihindari.
\end{abstract}

Kata Kunci: Pemikiran H.M. Rasjidi, Pendidikan Multikultural, Pendidikan Islam

\section{PENDAHULAN}

Di Indonesia, kondisi masyarakatnya sangat majemuk dalam hal keyakinan. Kemenag RI dalam buku "Moderasi Beragama" pada pembacaaan konteks masyarakat Muslim, memaparkan bahwa di masyarakat ini juga ada kemajemukan pada wilayah tafsir agama. Kemajemukan tafsir ini membuat kehidupan sosial semakin kompleks. Semua ini diakibatkan karena kemampuan kapasitas dan kemampuan berfikir masing-masing orang, perspektif, ataupun pendekatan. Selain itu, teks-teks agama memang besifat terbuka sehingga menimbulkan multi-interpretasi

(Kementerian Agama RI, 2019). Ditambah lagi, zaman globalisasi, teknologi, dan informasi, serta memasuki era disrupsi digital ini 
memberikan kemudahan kepada setiap ragam budaya untuk saling berinteraksi dan menimbulkan miskomunikasi. Ini merupakan kondisi realitas yang dapat memicu konflik karena adanya perbedaan. Keadaan itu, membutuhkan sebuah perspektif dan reformasi baru kepada pendidikan yang menjadi basis pembentukan peradaban. Salah satu tawaran untuk menghadapi perbedaann itu adalah pendidikan multikultural seperti yang dipelopori oleh James A. Bank (Waston dan Aly, 2018).

Sejalan dengan itu, Aneta Barakoska menyatakan bahwa prinsip multikultural dalam pendidikan didasari dari adanya modernisasi demokrasi masyarakat, hak, kebebasan, proses globalisasi, ekonomi, teknologi serta budaya (Barakoska 2013). Kondisi multikultural ini, sejalan dengan kondisi Indonesia sebagai bangsa yang besar, memiliki banyak budaya, suku, dan Agama. Bahkan, multikultural ini menjadi identitas Bangsa (Muthoifin, 2015), (Rachmawati et al, 2014).

Adapun studi kasus kota Solo, pendidikan multikultural dirasa menjadi kebutuhan yang mendesak. Kota Solo merupakan kota yang memiliki budaya dan keagamaan yang beragam. Dari BPS Kota yang disebut juga Surakarta, pada tahun 2018 memiliki 665 Masjid, 6 Gereja Katolik, 191 Gereja Kristen, 8 Kuil/ Vihara/Klenteng, 3 Pura, dan 244 Suraul/ Langgar/Mushola. Institusi pendidikan Islam memiliki 34 RA, 9 MIN/MIS, 8 MTSN/MTSS, 6 MAN/MAS dengan total peserta didik 13.114 siswa di tahun ajaran 2018/2019 (BPS Kota Surakarta, 2019).

Menurut Zakiyyudin Baidhawy, Solo merupakan salah satu tempat yang dapat merepresentasi dari realitas masyarakat plural dan multikultural yang kurang terkelola. Karena terdapat kelompokkelompok yang moderat, cair, dan garis keras. Kota ini juga dikenal sebagai kota persemaian benih-benih gerakan nasionalisme, sosialisme dan keagamaan.
Dalam sejarahnya belum terjadi konflik berdarah antar kelompok, namun potensi konflik di kota ini besar (Baidhawy, 2014). Konflik justru pernah terjadi dengan etnis China, meskipun sekarang sejak reformasi mereka menikmati kenyamanan bebasnya berbudaya dab beragama. Banyak orang china yang menjadi minooritas beragama Kristen, Katolik, Budha, dan Konfusionis (Mahfud 2018). Adanya isu konflik Agama di Asia yang dipicu ditindasnya umat Islam yang minoritas, membuat Muslim di Indonesia dan juga di Solo menjadi bergejolak (Fadlan dan Saputra, 2017). Gejolak-gejolak ini perlu untuk dikelola dengan wawasan multikulutral agar tidak menimbulkan keresahan dan disintegrasi bangsa.

Maka pendidikan multikultural menjadi sebuah kebutuhan untuk menghindari adanya konflik dikarenakan adanya pertemuan perbedaan tersebut. (Muthoifin, 2019) Salah satu tokoh Nasional dan tokoh modernisasi Islamterkhusus dari kalangan Muhammadiyah, yang memiliki pengalaman dialog antar Agama (interfaith dialogue) dan banyak berkarya tentang bagaimana menyikapi perbedaan -terkhusus Agama adalah Prof. HM Rasjidi. Makalah ini akan menggali bagaimana pemikiran Rasjidi dalam konsep Agama dan toleransi.

\section{METODE PENELITIAN}

Jenis penelitian yang digunakan adalah penelitian library research yang bertujuan untuk mengumpulkan data dan informasi dari bahan perpustakaan. Jenis penelitian ini adalah penelitian kualitatif-kepustakaan. Penelitian kualitatif merupakan jenis penelitian yang fokus terhadap penggalian makna interpretasi dari data-data. Adapun penelitian kepustakaan merupakan penelitian yang intinya adalah mempelajari dan membaca literaturliteratur. Menginterpretasikan hubungan objek penelitian dengan permasalahan 
yang dikaji. Atau dengan kata lain, sebuah penelitian yang serangkaian kegiatannya adalah pengumpulan data pustaka dari perpustakaan ataupub sumber otoritatif lainnya, kemudian memahaminya, mencatat, mengolah bahan penelitian dan mengambil kesimpulan (Mestika Zed, 2004).

\section{BIOGRAFI PROF. H.M. RASJIDI}

Prof. H.M. Rasjidi memiliki nama kecil atau nama asli yang diberikan oleh orang tauanya, yakni 'Saridi'. Bapak Sarini bernama Atmosudigyo, seorang pedagang kain, batik, perhiasan, dan berlian yang sukses. Ini yang membuat Saridi dan saudaranya Supardi, Sadjiman, Sakidjan, dan Sadjinah mampu mengenyam pendidikan tinggi (Ananda, 1985). Menurut Azra (1998), keluarga Saridi merupakan lingkungan keluarga yang termasuk abangan Islam Kejawen yang cenderung sinkretis. Dalam Azzani dan Harris (2019, p150), Saridi tumbuh dalam suasana bangsa yang sedang mengalami pergolakan yang besar melawan penjajah Belanda dan arus kristenisasi. Ini dapat dilihat dari cerita dalam salah satu karyanya yang berjudul "Mengapa Aku Tetap Memeluk Agama Islam" bahwa waktu itu bangsa Indonesia dalam keadaan bangkit degan adanya Syarikat Islam yang mengetuk jiwa perjuangan bangsa di tubuh umat Islam.

Saridi atas kehendak ayahnya pernah disekolahkan di sekolah Ongko Loro, sekolah Belanda setingkat SD yang menggunakan bahasa daerah sebagai pengantarnya. Setelah itu dipindah ke Sekolah Rakyat (SR) Muhammadiyah Kotagede, kemudian melanjutkan ke Kweecshool Muhammadiyah Kotagede. Setelah itu, Saridi belum merasa puas atas ilmu Agama yang diajarkan di sekolah tersebut dan menganggapnya tidak jauh dengan materi yang diajarkan di langgar-langgar. Ketika Saridi mulai suka membaca majalah dan surat kabar untuk menambah wawasannya, ia menemukan informasi bahwa Syaikh Syurkati alIrsyad pindah ke Kota Lawang, Jawa Timur untuk mendirikan pesantren. Saridi tertarik degan pesantren itu dan meminta izin Syaikh Surkati untuk ikut menjadi santrinya dengan mengirimkan surat. Di sini, Saridi merasa menemukan apa yang ia inginkan dalam belajar Islam. Dalam perkembangan intelektualnya di usia 15 tahun, ia mampu menghafal kitab "Matn al-Sullām al-Munawaraq", "Alfiyyah" Ibnu Malik, kitab nahwu dan bahkan buku terjemahan logika karya Aristoteles. Bagi Syaikh Surkati, nama Saridi susah untuk diucapkan, sehingga kemudian ia memanggi Saridi menjadi Rasjidi (Rasyidi). Nama ini dikukuhkan saat Saridi muda naik haji beberapa tahun kemudian setelah pertama kali dipanggil Rasjidi. Itulah sebab namanya kemudian lebih dikenal dengan nama Rasjidi. (Soebagijo dalam Ananda, 1985).

Rasjidi dan temannya di al-Irsyad kemudian atas arahan gurunya Syaikh Surkati, mereka melanjutkan studi ke Kairo, Mesir. Setelah selesai dari alQism al-'Ām dan mendapatkan ijazah 'Aliyyah, Rasjidi melanjutkan ke Dār al'Ulūm dengan diantarkan oleh Syaikh Tanțawī Jauhārī. Saat di Universitas Dār 'Ulūm, Rasjidi bertemu Rashīd Ridā, Sayyid Quṭb, Muștafā 'Abd Rāziq. Selain itu juga bertemu beberapa sarjana Barat yang mengajar di Dār 'Ulūm seperti Alexandre Koyre and Andre Lalande. Sebelum menamatkan studinya di Dār 'Ulūm dengan predikat sangat terpuji, Rasjidi menghafal Al-Qur'an 30 juz serta dan mengikuti kursus Bahasa Perancis. Setelah itu Rasjidi kembali ke Indonesia dan banyak bergelut di ranah politik dan menjadi Menteri Agama Pertama RI serta menjadi Duta Besar beberapa negara Timur Tengah (Azzani dan Harris, 2019, p151).

Di Tahun 1956, Rasjidi berhasil menyelesaikan studi PhD dengan predikat 
Summa Cam Laude dari Universitas Sorbonne, Perancis. Di sini Rasjidi dibimbingan langsung oleh salah satu tokoh Orientalis yang dikenal sebagai pakar tasawwuf Islam, Louis Massignon (Rasjidi, 1967). Kemudian, karena kecerdasannya dan sepakterjangnya, Rasjidi diundang oleh Wilfred C. Smith sebagai dosen pertama dari Indonesia dengan gelar Associate Professor (19581963) di Universitas McGill, Montreal, Canada selama lima tahun. Setelah itu Rasjidi menjadi direktur Islamic Centre di Washington D.C. (Azzani dan Harris, 2019, p152).

Dari melihat perjalanan intelektual Rasjidi di Jawa Timur, Timur Tengah dan Barat tersebut, membuat ia memiliki otoritas dalam membicarakan kelebihan dan kekurangan budaya serta pemikiran orientalis Barat terhadap studi Islam. Adapun jika melihat beberapa karyakaryanya, dan buku yang mengkritik juniornya sendiri yakni Nurcholis Majid dan Harun Nasution, memberikan keterangan kuatbahwa Rasjidi merupakan tokoh intelektual Islam Indonesia yang kokoh berusaha tidak terpengaruh oleh pola berfikir nalar orientalis.

\section{KARYA-KARYA HM RASJIDI}

Azzani dan Harris dalam penelitiannya yang berjudul "Islam Dan Modernisme: Di Indonesia: Kontribusi Pemikiran Mohamad Rasjidi (1915-2001)" menemukan karya-karya Rasjidi cukup lengkap. Diantaranya adalah buku yang diteliti dalam artikel ini yakni "Empat Kuliah Agama Islam pada Perguruan Tinggi", Jakarta: Bulan Bintang, 1974 dan "Koreksi Terhadap Dr. Harun Nasution Tentang Islam ditinjau dari Berbagai Aspeknya", Jakarta: Bulan Bintang 1977. Selain daripada itu ada juga makalah yang telah diterbitkan yang sebagiannya disunting dalam sebuah buku yang berbentuk kumpulan makalah. Terdapat juga tulisan beliau dari perbagai surat kabar dan hasil wawancara yang menyinggung persoalan Agama-agama : (1) "Unity and Diversity in Islam" dalam Islam the Straight Path, ed. Kenneth W. Morgan, New York: The Ronald Press: 1958; 1987; 1993, (2) “Usaha MengKristiankan Indonesia dan Dunia" Suara Muhammadiyah, 1-2 Januari, 1968, (3) "Sambutan Atas Kedatangan Sri Paus Paulus IV di Indonesia, 3 Desember, 1970" dalam Dari Rasjidi dan Maududi Kepada Paus Paus Paulus VI, ed. S.U. Bajasut, Surabaya: DDII Perwakilan Djatim dan Penerbit Documenta, 1971, (4) "The Role of Christian Missions, the Indonesian Experience", International Review of Mission Vol. 65 No. 260, October, 1976, 425-38, (5) "Islam dan Kristian di Indonesia," Panji Masyarakat No. 258, November, 1978; 10-14. (Azzani dan Harris, 2019, p152-155)

\section{PEMIKIRAN H.M. RASJIDI TENTANG AGAMA DAN TOLERANSI \\ Memperjelas Perbedaan Antar Agama}

Indonesia ini terdapat sesuatu pendapat yang tersebar luas meskipun tidak merata. Pendapat itu menyatakan, bahwa semua agama itu sama; tujuan agama-agama itu sama, yaitu mendorong kita untuk melakukan yang baik dan menghindari kejahatan, serta hubungan dengan Tuhan Yang Maha Kuasa. Hanya caranya berlainan. Orang Islam pada hari Jum'at pergi ke Masjid, orang Kristen pada hari Ahad ke Gereja, sedangkan orang Hindu memuja di suatu candi, atau di tempat yang sunyi jauh dari tempattempat yang ramai, melakukan meditasi. HM Rasjidi dalam bukunya "Empat Kuliah Agama Islam Pada Perguruan Tinggi", menegaskan bahwa setiap Agama memiliki perbedaan. Pendapat yang menyamakan semua agama dalam berbagai pendekatan ia tolak (Rasjidi, 1974, p24).

Ketidaksepakatan Rasjidi atas kesamaan semua Agama, ia tunjukkan dari beberapa pendekatan. Pertama, dari 
definisi. Islam menurut Rasjidi adalah 'al-Dīn' dengan berbahasa Arab yang maknanya tidak sama dengan bahasa lain seperti kata 'Agama' yang berasal dari bahasa Sanskrit dan 'Religion' dari bahasa Latin. Rasjidi menegaskan:

"Kata Agama lebih menonjolkan soal tradisi, dan religion menonjolkan ikatan manusia dengan kelompoknya di samping dewanya. Kata religion pun tidak ada dalam Injil, sedang kata aldin ada dalam al-Qur'an yang konotasinya sangat berlawan dengan kata agama atupun religion. Memang kita menterjemahkan al-dīn dengan agama, atau kalau memakai bahasa barat kita memakai religion, akan tetapi hal itu sekedar untuk mempermudah berkomunikasi dengan orang banyak. Dalam hakekatnya, al-dìn bukan tradisi saja dan bukan religion saja atau ikatan saja" (Rasjidi, 1977, p15).

Kedua, dari aspek teologi. Rasjidi menukilkan pandangan Randhakrisna mengenai realitas transenden agamaagama. Peraktaan-perkataan, lambanglambang, dogma-dogma dan sebagainya adalah khusu perkakas untuk mencapai realisasi daripada yang ilahi dalam diri manusia. Agama tak ada yang mengandung sesuatu yang mutlak, semua agama relatif dan instrumentalis, dan bermakna untuk mencapai tujuan. Rasjidi menolak paham seperti ini dengan menukilkan kitab agama lain yakni agama Kristen, ia mengatakan:

"Sebenarnya sinkretisme Radhakrisnan ini sangat berbahaya. Ia adalah suatu pengiaan terhadap bisikan iblis: "Kamu akan menjadi seperti Allah". (Kitab Kejadian 3:5). Sikretisme ini antroposentris secara radikal dan bukan teosentris. "Dalam rumah untuk agama-agama yang dibangun Randhakrisnan dalam mimpinya ini, banyak tempat untuk tempat tinggal", demikianlah dikemukakan Kraemer dengan tepat, tetapi tidak untuk Tuhan, yang benar-benar Tuhan" (Rasjidi, 1974, p33-34).

Ketiga, dari aspek sejarah. Rasjidi menerangkan berbagai problematika antar agama di Barat dan historisitas Islam yang berbeda dengan agama lain. Agama-agama itu berbeda satu dengan yang lain, bahkan perbedaan itu terkadang sedemikian prinsipilnya sampai memusuhi dan memerangi umat agama lain. Rasjidi mengatakan:

"di samping itu, tinjauan sejarah tersebut menyakinkan kita bahwa perbedaan-perbedaan dalam agama itu tidak bisa dielakkan. Ini adalah realitas dunia yang telah kita lihat bersama di masa lampau dan yang kini sedang pula kita hadapi. Kita tak dapat menutup mata kita san pura-pura bersikap bahwa perbedaan itu tidak ada, karena sikap yang demikian itu pada suatu ketika dapat menjerumuskan kita kembali dalam malapetaka yang mungkin lebih dahsyat dari pada yang pernah dialami oleh umat manusia" (Rasjidi 1974, p45-46).

\section{Perbedaan Sebagai Asas Toleransi}

Toleransi menurut HM Rasjidi adalah konsekuensi pokok dari penerimaan dan kesadaran terhadap semua agama itu berbeda. Dalam melihat realitas yang tidak bisa dielakkan tersebut, sebaik-baik sikap yang harus kita ambil ialah agar masing-masing menyadari benar-benar adanya perbedaan itu. Karena kedasaran itu berkonsekuensi harus bersikap toleran terhadap umat lain secara sungguhsungguh, baik dalam kata maupun tindakan. Dekrit Nantes dan Penrjanjian Westphalia adalah saksi terjadinya permusuhan dan peperangan agama yang 
mengajarkan tentang toleransi (Rasjidi, 1974, p46).

Agama Islam menurut HM Rasjidi, merupakan agama Samawi yang berbeda dengan agama lain yang berupa gejala sosial budaya. Sebagaimana yang dikemukakan oleh Dr. Harun Nasution yang membagi Agama itu seperti Genus yang memiliki beberapa Spesies. HM Rasjidi menolak ini dan menegaskan bahwa masalah agama bukan persoalan genus saja, melainkan dari agama kebudayaan dan agama Samawi (Rasjidi, 1977, p25). Konsep toleransi atas perbedaan tersebut, menurut HM Rasjidi ia kemukakan sebagai berikut:

Bagi pemeluk agama Islam, soal toleransi ini terdapat dalam a-Qur'an, syrat Haj, ayat 39 dan 40 yang kira-kira artinya:

"Tentu izin perang diberikan kepada orang yang telah diperangi, karena sesungguhnya mereka itu telah dirugikan. Sungguh, Allah Maha Kuasa untuk menolong mereka itu. Yaitu oran-orang yang diusir dari kempung halaman mereka tanpa alasan, kecuali karena mereka berkata: Tuhan kami hanyalah Allah. Sekiranya Allah telah menahan sekelompok manusia dengan kelompok yang lain, tentulah biara-biara Nasrani,gereja-gereja, rumah-rumah ibadat Yahudi dan mesjid-mesjid yang didalamnya banyak disebut nama Allah, sudah dihancurkan. Sudah pasti, Allah akan menolong mereka yang menolong agamaNya. Sungguh Allah itu Maha Kuasa dan Perkasa". (Rasjidi 1974, p46).

Selain dari al-Qur'an, HM Rasjidi juga menukilkan dikumen Vatikan.

"Dalam ranka toleransi antara lain telah ditentukan bahwa orang yang menyiarkan sesuatu agama, tidak diperbolehkan memakai paksaan, baik paksaan kasar maupu Dn halus, ya'ni dengan mempergunakan daya penarik materiil. Seperti dalam "Document of Vaticant II" dibawah judul "Religious Freedom" memuat sebagai berikut: "However. In spreading religious faith and in intriducing religious practices, every one ought at all times to refrain from any manner of action which might seem to carry a hint of ceorcion or of a kind of persuasion that would be dishounourable or unworthy, especially when dealing with poor or uneducated people. Such a manner of action would have to be considered an abuse of one's own right and a violation of the right of others." (Rasjidi, 1974, p46-47).

\section{IMPLIKASI PEMIKIRAN HM RASJIDI TERHADAP KONSEP PENDIDIKAN MULTIKULTURALISME}

Dewasa ini, pendidikan multikulturalisme memiliki berbagai definisi dan konsep. Konsep ini menjadi arus diskusi utama dalam politik, diskursus intelektual, dan teori sosial (Maowad dan El Shoura, 2017; Mishra dan Kumar, 2014). Cambridge University menerbitkan "The Cambridge Handbook of Acculturation Psychology (2016)", salah satu babnya membahas 'Multiculturalism'. Konsep multikulturalisme di seluruh dunia, selama 40an tahun kebelakang, telah memiliki berbagai pengertian yang berbeda (Berry dan Ward, 2016).

Mengacu pada pemikiran HM Rasjidi, maka pendidikan multikultural harus selektif dalam mengambil teori, terutama yang menyangkut pada aspek teologis dan penyamaan semua agama (pluralisme agama) dalam pendidikan multikulturalisme. Pemikiran HM Rasjidi tentang tidak bolehnya menyamakan semua agama, relevan dengan fatwa MUI. Yakni mengenai adanya fatwa yang mengharamkan Pluralisme Agama. Jadi, maksud pluralisme disini adalah paham yang menyamakan dan mencampuradukkan. 
Adapun pluralitas, sebagai pemahaman atas adanya perbedaan adalah dibolehkan dan sebagai sebuah keniscayaan. Maksud terma pluralisme disini adalah membenarkan dan menyamakan semua Agama, bukan sebagaimana yang dipahami masyarakat yang memahami pluralisme adalah pengakuan atas adanya Agama lain, yang ternyata sebenarnya pemahaman itu mengacu kepada konsep pluralitas (Ryandi, 2013). Sedang multikultural dapat diartikan sebagai kondisi akan adanya perbedaan di sekitar yang perlu diakui.

Untuk menengahi perdebatan itu, maka penting untuk mendudukkan definisi apa yang dimaksud multikultural dan multikulturalisme dalam mengkonsep pendidikan berwawasan multikultural. Hal ini akan berimplikasi kepada kurikulum dan materi penyampaian. Sebagaimana yang diutarakan sebelumnya mengenai definisi, sejarah dan teologi Agama dalam perkuliahan sangat penting disampaikan dengan jelas mengenai adanya perbedaan di semua Agama, tidak sebagaimana buku Dr. Harun Nasution yang dikritik HM Rasjidi. Pendidikan multikultural jika mengacu kepada konsep agama dan toleransi HM Rasjidi, dapat diarahkan kepada pendidikan yang memberikan pendewasaan dan pengarahan untuk memahami perbedaan yang ada. Sehingga harapannya dari pengajaranpengajaran kedewasaan dan kesadaran akan perbedaan itulah toleransi dapat dijalankan secara sungguh-sungguh.

\section{KESIMPULAN}

Berdasarkan pemikiran HM Rasjidi tentang tegasnya dalam membedakan semua Agama, maka dapat disimpukan, bahwa HM Rasjidi menempatkan realitas perbedaan sebagai asas toleransi. Kemudian, pendidikan multikultural dapat diarahkan kepada: pertama, pendidikan multikultural adalah pendidikan pendewasaan atas khasanah perbedaan dari segi definisi agama, konsep teologi dan sejarahnya. Kedua, kesadaran akan perbedaan berimplikasi kepada definisi dan muatan materi multikultural dan multikulturalisme. Ketiga, pembangunan sikap toleransi yang sungguh-sungguh dengan tetap mempertahankan perbedaan-perbedaan yang ada.

\section{DAFTAR PUSTAKA}

Ananda E.B. (ed).1985. 70 Tahun Prof. Dr. H.M. Rasjidi. Jakarta: Harian Umum Pelita.

Azzani, M.Z., \& Harris, K.M.A. 2019. Islam dan Modernisme di Indonesia: Tinjauan atas Pemikiran Mohamad Rasjidi (1915-2001). Jurnal Tsaqafah, 15, 147-164. doi: 10.21111/tsaqafah.v15il.2831

Azra, Azyumardi. 1998. "H.M. Rasjidi, BA, Pembentukan Kementerian Agama Dalam Revolusi". Dalam Saiful Umam (ed), Menteri-Menteri Agama RI: Biografi Sosial Politik. Jakarta: INIS bekerjasama dengan PPIM dan Balitbang Depag.

Baidhawy, Zakiyyudin. 2014. Muatan Nilai-Nilai Multikultural dan Anti-Multikultural dari Mimbar Masjid di Kota Solo. Jurnal Analisa, 21, 173-174. Doi: 10.18784/analisa. v21i02.13

Barakoska, A. 2013. Multiculturalism as Important Characteristic of Contemporary Education. International Journal of Cognitive Research in science, engineering and education (IJCRSEE), 1. 
PROFETIKA, Jurnal Studi Islam, Vol.21, No. 1, Special Issue 2020: 91-98

BPS Kota Surakarta. 2019. Kota Surakarta Dalam Angka. Surakarta: BPS Kota Surakarta. ISSN: 0215-6164

Fadlan, M.N., \& Saputra, R.E. 2017. Islam, Radicalism, Democracy, and Global Trends in Southeast Asia. Jurnal Studia Islamika, 24, 634-647. doi: 10.15408/sdi.v24i3.6566

Kementerian Agama RI. 2019. Moderasi Beragama. Jakarta: Badan Litbang dan Diklat Kementerian Agama RI.

Mahfud, C. 2018. Chinese Muslim Community Development in Contemporary Indonesia: Experiences of PITI in East Java. Jurnal Studia Islamika, 2, 471-498. doi: 10.15408/sdi.v25i3.6755

Maowad, N.M.I., \&ElShoura,S.M.2017. TowardARicherDefinitionOfMulticulturalism. International Journal of Advance Research, 2, 802-806. doi: 10.21474/IJAR01/4783

Mishra, S., \& Kumar, C.B. 2014. Understanding Diversity: A Multicultural Perspective. IOSR Journal Of Humanities And Social Science (IOSR-JHSS), 19, 62-66. e-ISSN: 2279-0837

Muthoifin. 2015. Pemikiran Pendidikan Multikultural Ki Hadjar Dewantara, dalam Jurnal Intizar, Vol. 21, No. 2: 299.

Muthoifin, 2019. Humanist islam in Indonesia Ahmad Syafii Maarif perspective, Journal Humanities and Social Sciences Reviews. Vol 7, No 6, 2019, pp 780-786.

Rachmawati, Y., Yi-Wong, P., \& Chen, Hua-Hua. 2014. The Necessity Of Multicultural Education In Indonesia. International Journal of Education and Research, 2. 317-328 ISSN: 2201-6740 (Online).

Rasjidi, H.M. 1974. Empat Kuliah Agama Islam Pada Perguruan Tinggi. Jakarta: Penerbit Bulan Bintang.

1977. Koreksi Terhadap Dr. Harun Nasutioan tentang "Islam Ditinjau dari Berbagai Aspeknya". Jakarta: Penerbit Bulan Bintang.

Ryandi. 2013. Antara Pluralisme Liberal dan Toleransi. Jurnal Kalimah, 11, 252-270.

Sam, D.L., (ed) \& Berry J.W. (ed). 2017. The Cambridge Handbook of Acculturation Psychology. UK: Cambridge University Press. doi: http://dx.doi.org/10.1017/ CBO9781316219218.

Waston \& Aly, A. 2018. Pendidikan Multikultural dalam Perguruan Tinggi Islam Sebuah Implementasi Konseptual Pemikiran James A. Banks. Prosiding Konferensi Nasional Ke- 8 Asosiasi Program Pascasarjana Perguruan Tinggi Muhammadiyah (APPPTMA). ISBN: 978-602-50710-9-6

Zed, Mestika. 2004. Metode Penelitian Kepustakaan. Jakarta: Yayasan Obor Indonesia. 